\title{
Hubungan antara Indeks Massa Tubuh dan Lingkar Perut dengan Tekanan Darah pada Siswa SMA Kristen 2 Binsus Tomohon
}

\author{
Winny G. Rindorindo, ${ }^{1}$ Ivonny M. Sapulete, ${ }^{2}$ Erwin A. Pangkahila ${ }^{2}$
}

\author{
${ }^{1}$ Program Studi Pendidikan Dokter Fakultas Kedokteran Universitas Sam Ratulangi Manado \\ ${ }^{2}$ Bagian Fisiologi Fakultas Kedokteran Universitas Sam Ratulangi Manado \\ Email: winnyrindorindo@gmail.com
}

\begin{abstract}
Adolescence is a vulnerable age group to nutrition imbalance disorders. One complication of high anthropometric level is increased blood pressure or hypertension. This study was aimed to determine the relationship between body mass index and waist size to blood pressure among senior high school students in Tomohon. This was an analytical observational study with a cross sectional design. Subjects were 307 students of SMA Kristen 2 Binsus Tomohon consisting of 139 males and 168 females. Measurement of weight, height, and waist circumference (WC) as well as calculation of body mass index (BMI) were performed on all subjects. The Kolmogorof-Smirnov test showed that the data were not distributed normally. The Spearman correlation test obtained a p-value of $0.000(p<0.05)$ for the correlation between BMI and WC to blood pressure (systolic and diastolic blood pressures). In conclusion, there were significant relationships between BMI and blood pressure as well as between waist circumference and blood pressure.
\end{abstract}

Keywords: body mass index, waist size, blood pressure

\begin{abstract}
Abstrak: Usia remaja sangat rentan terhadap gangguan keseimbangan gizi. Salah satu komplikasi dari nilai antopometri yang tinggi ialah naiknya tekanan darah (hipertensi). Penelitian ini bertujuan untuk mengetahui hubungan antara indeks massa tubuh (IMT) dan lingkar pinggang (LP) dengan tekanan darah pada siswa SMA di Kota Tomohon. Jenis penelitian ialah analitik observasional dengan desain potong lintang. Subyek penelitian ialah siswa SMA Kristen 2 Binsus Tomohon yang berjumlah 307 siswa terdiri dari 139 laki-laki dan 168 perempuan. Pengukuran berat badan, tinggi badan, lingkar pinggang dan penghitungan IMT dilakukan pada seluruh subyek penelitian. Hasil uji normalitas Kolmogorof-Smirnov memperlihatkan data tidak terdistribusi normal, dilanjutkan dengan metode nonparametric correlation menggunaakan uji Spearman yang mendapatkan nilai $\mathrm{p}=0,000(\mathrm{p}<0,05)$ untuk hubungan antara IMT dan LP dengan tekanan darah baik sistol maupun diastol. Simpulan penelitian ini ialah terdapat hubungan bermakna antara indeks massa tubuh dan lingkar pinggang dengan tekanan darah.
\end{abstract}

Kata kunci: indeks massa tubuh, lingkar pinggang, tekanan darah

\section{PENDAHULUAN}

Tekanan darah adalah suatu bentuk gaya yang diberikan oleh darah terhadap dinding pembuluh darah yang dipengaruhi oleh volume darah, daya regang, dan dinding pembuluh darah. Terdapat dua jenis tekanan yang dapat diukur yaitu tekanan sistol dan tekanan diastol. Tekanan sistol adalah tekanan maksimal yang ditimbukan pada arteri, sedangkan tekanan diastole adalah tekanan minimal yang ditimbulkan pada arteri. ${ }^{1}$

Indeks massa tubuh (IMT) merupakan suatu indikator untuk menghitung status gizi orang khususnya yang berkaitan dengan kekurangan berat badan, kelebihan berat badan dan obesitas. ${ }^{2}$ Status gizi merupakan salah satu indikator yang menentu- 
kan kualitas sumber daya manusia. ${ }^{3}$ Lingkar pinggang merupakan suatu indikator sederhana untuk menentukan status obesitas sentral. ${ }^{4}$ Indeks massa tubuh dan lingkar pinggang merupakan bagian dari perhitungan antropometri. Yang membedakannya ialah IMT dapat menentukan status gizi tubuh keseluruhan tetapi lingkar pinggang menandai status gizi bagian abdominal yang berkaitan dengan obesitas sentral., Saat ini terdapat berbagai metode pengukuran antropometri tubuh yang dapat digunakan sebagai skrining obesitas. Metode tersebut antara lain pengukuran IMT, lingkar pinggang, lingkar panggul, lingkar lengan atas, serta perbandingan lingkar pinggang dan lingkar panggul. ${ }^{5}$

Usia remaja merupakan usia yang rentan terjadi gangguan keseimbangan gizi. Salah satu penyebabnya yaitu tingkat kebutuhan gizi yang lebih tinggi untuk kebutuhan pertumbuhan di masa remaja. Gaya hidup sering berubah karena terjadinya perubahan zaman yang diikuti dengan perubahan gaya hidup dan pola makan. Remaja sering menjadi kelompok sasaran yang berisiko mengalami gizi lebih. Gizi lebih dapat ditandai dengan berat badan yang relatif berlebihan bila dibandingkan dengan tinggi badan. ${ }^{6,7}$

Data riset kesehatan dasar (Riskesdas) 2013 menyatakan bahwa persentase kasus hipertensi pada tahun 2013 mengalami kenaikan sebesar $1,90 \%$. Kasus hipertensi terbanyak di Indonesia terjadi pada kelompok usia 18 tahun keatas dengan jumlah persentase $25,80 \%$. Provinsi dengan prevalensi hipertensi tertinggi yaitu provinsi Sulawesi Utara dengan persentase $27 \%$. $^{8}$

Sebelum melakukan penelitian, penulis telah melakukan survei awal menghubungi pihak sekolah yaitu kepala sekolah dan wakil kepala sekolah bidang kesiswaan. Dari hasil survei peneliti mendapatkan informasi bahwa siswa di SMA Kristen 2 Binsus Tomohon memiliki IMT yang beragam, mulai dari IMT rendah, normal, berlebih, bahkan sampai obesitas. Berdasarkan uraian ini, penulis tertarik untuk meneliti hubungan antara IMT dan lingkar pinggang terhadap tekanan darah pada siswa SMA Kristen 2 Binsus Tomohon.

\section{METODE PENELITIAN}

Penelitian ini bertujuan untuk meneliti hubungan antara IMT dan lingkar pinggang dengan tekanan darah pada siswa SMA Kristen 2 Binsus Tomohon. Jenis penelitian ini ialah analitik obsevasional yang menggunakan desain potong lintang.

Pada penelitian ini terdapat 307 siswa yang menjadi subyek penelitian. Seluruh subyek diukur tinggi badan, berat badan, lingkar pinggang dan tekanan darah dengan menggunakan alat microtoise, timbangan badan, meteran, sfigmomanometer, dan stetoskop secara berurut. Data hasil penelitian diolah secara statistik menggunakan analisis uji Spearman.

\section{HASIL PENELITIAN}

Pada penelitian ini terdapat 307 siswa yang menjadi subyek penelitian, terdiri dari $139(45,3 \%)$ berjenis kelamin laki-laki dan $168(54,7 \%)$ berjenis kelamin perempuan. Tabel 1 memperlihatkan distribusi subyek penelitian berdasarkan usia; yang terbanyak ialah subyek berusia 16 tahun berjumlah 106 siswa $(34,5 \%)$ dan yang paling sedikit ialah subyek berusia 13 tahun berjumlah 1 siswa (3\%).

Tabel 1. Distribusi subyek penelitian berdasarkan usia

\begin{tabular}{ccc}
\hline $\begin{array}{c}\text { Usia } \\
\text { (tahun) }\end{array}$ & $\begin{array}{c}\text { Frekuensi } \\
(\mathbf{n})\end{array}$ & $\begin{array}{c}\text { Persentase } \\
(\%)\end{array}$ \\
\hline 13 & 1 & 3 \\
14 & 50 & 16,3 \\
15 & 94 & 30,6 \\
16 & 106 & 34,5 \\
17 & 54 & 17,6 \\
18 & 2 & 7 \\
Total & 307 & 100 \\
\hline
\end{tabular}

Tabel 2 memperlihatkan distribusi subyek berdasarkan berat badan; yang terbanyak ialah subyek dengan berat badan 41-60 kg yaitu 213 siswa $(69,4 \%)$ sedangkan yang paling sedikit ialah subyek dengan berat badan $>100 \mathrm{~kg}$ yaitu 3 siswa $(1 \%)$. 
Tabel 2. Distribusi subyek penelitian berdasarkan berat badan

\begin{tabular}{ccc}
\hline $\begin{array}{c}\text { Berat badan } \\
(\mathbf{k g})\end{array}$ & $\begin{array}{c}\text { Frekuensi } \\
(\mathbf{n})\end{array}$ & $\begin{array}{c}\text { Persentase } \\
(\boldsymbol{\%})\end{array}$ \\
\hline$\leq 40$ & 9 & 2,9 \\
$41-60$ & 213 & 69,4 \\
$61-80$ & 71 & 23,1 \\
$81-100$ & 11 & 3,6 \\
$>100$ & 3 & 1 \\
Total & 307 & 100 \\
\hline
\end{tabular}

Tabel 3 memperlihatkan distribusi subyek berdasarkan tinggi badan; yang terbanyak ialah subyek dengan tinggi badan $156-165 \mathrm{~cm}$ yaitu 120 siswa $39,1 \%$ ) dan yang paling sedikit ialah subyek dengan tinggi badan $\leq 145 \mathrm{~cm}$ yaitu 5 siswa $(1,6 \%)$.

Tabel 3. Distribusi subyek penelitian berdasarkan tinggi badan

\begin{tabular}{ccc}
\hline $\begin{array}{c}\text { Tinggi } \\
\text { badan } \\
(\mathbf{c m})\end{array}$ & $\begin{array}{c}\text { Frekuensi } \\
(\mathbf{n})\end{array}$ & $\begin{array}{c}\text { Persentase } \\
(\boldsymbol{\%})\end{array}$ \\
\hline$\leq 145$ & 5 & 1,6 \\
$146-155$ & 95 & 30,9 \\
$156-165$ & 120 & 39,1 \\
$166-175$ & 80 & 26,1 \\
$\geq 176$ & 7 & 2,3 \\
Total & 307 & 100 \\
\hline
\end{tabular}

Tabel 4 memperlihatkan kelompok IMT dari 307 subyek.; yang terbanyak ialah kelompok IMT 18,5-22,9 berjumlah 170 siswa $(55,4 \%)$ dan yang paling sedikit ialah kelompok IMT $\geq 30$ berjumlah 13 siswa $(4,2 \%)$.

Tabel 4. Distribusi subyek penelitian berdasarkan IMT

\begin{tabular}{ccc}
\hline IMT & $\begin{array}{c}\text { Frekuensi } \\
(\mathbf{n})\end{array}$ & $\begin{array}{c}\text { Persentase } \\
(\boldsymbol{\%})\end{array}$ \\
\hline$<18.5$ & 39 & 12,7 \\
$18,5-22,5$ & 170 & 55,4 \\
$23-24,9$ & 47 & 15,3 \\
$25-29,9$ & 38 & 12,4 \\
$\geq 30$ & 13 & 4,2 \\
Total & 307 & 100 \\
\hline
\end{tabular}

Tabel 5 memperlihatkan kelompok lingkar pinggang pada subyek laki-laki.
Dari 139 subyek laki-laki, yang terbanyak ialah subyek dengan lingkar pinggang <94 $\mathrm{cm}$ yaitu 125 siswa $(89,9 \%)$ dan yang paling sedikit ialah subyek dengan lingkar pinggang $>102 \mathrm{~cm}$ yaitu 5 siswa $(3,6 \%)$.

Tabel 5. Distribusi subyek penelitian laki-laki berdasarkan lingkar pinggang

\begin{tabular}{ccc}
\hline $\begin{array}{c}\text { Lingkar pinggang } \\
(\mathbf{c m})\end{array}$ & $\begin{array}{c}\text { Frekuensi } \\
(\mathbf{n})\end{array}$ & $\begin{array}{c}\text { Persentase } \\
(\boldsymbol{\%})\end{array}$ \\
\hline$>102$ & 5 & 3,6 \\
$94-102$ & 9 & 6,5 \\
$<94$ & 125 & 89,9 \\
Total & 139 & 100 \\
\hline
\end{tabular}

Tabel 6 memperlihatkan kelompok lingkar pinggang pada subyek perempuan. Dari 168 subyek perempuan, yang terbanyak ialah subyek dengan lingkar pinggang $<80 \mathrm{~cm}$ yaitu 126 siswa $(75 \%)$ dan yang paling sedikit ialah subyek dengan lingkar pinggang $>88 \mathrm{~cm}$ yaitu 12 siswa $(7,1 \%)$.

Tabel 6. Distribusi subyek penelitian perempuan berdasarkan lingkar pinggang

\begin{tabular}{ccc}
\hline $\begin{array}{c}\text { Lingkar pinggang } \\
(\mathbf{c m})\end{array}$ & $\begin{array}{c}\text { Frekuensi } \\
(\mathbf{n})\end{array}$ & $\begin{array}{c}\text { Persentase } \\
(\boldsymbol{\%})\end{array}$ \\
\hline$>88$ & 12 & 7,1 \\
$80-88$ & 30 & 17,9 \\
$<80$ & 126 & 75,0 \\
Total & 168 & 100 \\
\hline
\end{tabular}

Tabel 7 memperlihatkan distribusi tekanan darah sistol (TDS) pada subyek penelitian; yang terbanyak ialah subyek dengan TDS $\leq 120 \mathrm{mmHg}$ berjumlah 281 siswa $(91,5 \%)$ sedangkan yang paling sedikit ialah subyek dengan TDS 140-159 mmHg yaitu 5 siswa $(1,6 \%)$.

Tabel 7. Distribusi sampel berdasarkan tekanan darah sistol (TDS)

\begin{tabular}{ccc}
\hline $\begin{array}{c}\text { TDS } \\
(\mathbf{m m H g})\end{array}$ & $\begin{array}{c}\text { Frekuensi } \\
(\mathbf{n})\end{array}$ & $\begin{array}{c}\text { Persentase } \\
(\boldsymbol{\%})\end{array}$ \\
\hline$\leq 120$ & 281 & 91,5 \\
$121-139$ & 21 & 6,8 \\
$140-159$ & 5 & 1,6 \\
Total & 307 & 100 \\
\hline
\end{tabular}


Tabel 8 memperlihatkan distribusi tekanan darah diastol (TDD) pada subyek penelitian; yang terbanyak ialah subyek dengan TDD $\leq 80 \mathrm{mmHg}$ yaitu 202 siswa $(65,8 \%)$ sedangkan yang paling sedikit ialah subyek dengan TDD $\geq 100 \mathrm{~mm} \mathrm{Hg}$ yaitu 4 siswa $(1,3 \%)$.

Tabel 8. Distribusi subyek penelitian berdasarkan tekanan darah diastol

\begin{tabular}{ccc}
\hline $\begin{array}{c}\text { TDD } \\
(\mathbf{m m H g})\end{array}$ & $\begin{array}{c}\text { Frekuensi } \\
(\mathbf{n})\end{array}$ & $\begin{array}{c}\text { Persentase } \\
(\mathbf{\%})\end{array}$ \\
\hline$<80$ & 202 & 65,8 \\
$80-89$ & 79 & 25,7 \\
$90-99$ & 22 & 7,2 \\
$\geq 100$ & 4 & 1,3 \\
Total & 307 & 100 \\
\hline
\end{tabular}

Uji korelasi terhadap hubungan antara IMT dan TDS mendapatkan nilai $\mathrm{r}=0,429$ dan $\mathrm{p}=0,000(\mathrm{p}<0,05)$ sedangkan terhadap hubungan antara IMT dan TDD mendapatkan nilai $\mathrm{r}=0,286$ dan $\mathrm{p}=0,000(\mathrm{p}<0,05)$. Uji korelasi terhadap hubungan antara lingkar pinggang dan TDS mendapatkan nilai $r=0,485$ dan $p=0,000 \quad(p<0,05)$, sedangkan terhadap hubungan antara lingkar pinggang dan TDD mendapatkan nilai $\mathrm{r}=0,353$ dan $\mathrm{p}=0,000(\mathrm{p}<0,05)$.

\section{BAHASAN}

Faktor penyebab obesitas pada remaja bersifat multifaktorial. Peningkatan konsumsi makanan cepat saji (fast food), rendahnya aktivitas fisik, faktor genetik, faktor psikologis, status sosial ekonomi, program diet, usia, dan jenis kelamin merupakan faktor-faktor yang berkontribusi pada perubahan keseimbangan energi dan berujung pada kejadian obesitas. ${ }^{9}$ Pada penelitian ini didapatkan adanya hubungan antara IMT dengan tekanan darah baik TDS maupun TDD $(\mathrm{p}=0,000)$. Hasil yang sejalan dilaporkan oleh Amasyitha et $\mathrm{al}^{10}$ yang mendapatkan hubungan antara IMT dengan tekanan darah, dan lebih dari $50 \%$ siswa dengan status gizi berlebih memiliki tekanan darah yang tergolong tinggi di SMPN 40 Bandung. Penelitian yang serupa juga dilakukan oleh Sumayku et $\mathrm{al}^{6}$ terha- dap mahasiswa Fakultas Kedokteran Universitas Sam Ratulangi Manado tahun 2013, dan didapatkan hubungan bermakna dan erat antara IMT dengan tekanan darah. Hasil penelitian ini tidak selaras dengan penelitian yang dilakukan oleh Sarah et al ${ }^{11}$ di sekolah dasar Kota Medan yang menyatakan bahwa hubungan antara IMT dengan tekanan darah sangat lemah, namun dengan jumlah sampel penelitian yang terbatas.

Peningkatan IMT erat kaitannya dengan penyakit hipertensi baik pada laki-laki maupun perempuan. Kenaikan berat badan sangat berpengaruh pada mekanisme timbulnya kejadian hipertensi pada individu yang obes akan tetapi mekanisme tersebut belum dipahami secara jelas. Terdapat beberapa hal yang diduga turut berperan yaitu pada individu dengan IMT berlebih terjadi peningkatan volume plasma dan curah jantung sehingga jantung akan berkerja lebih keras untuk memompakan darah yang akan menyebabkan naiknya tekanan darah. ${ }^{6,12,13}$

Pada penelitian ini didapatkan adanya hubungan erat antara lingkar pinggang dengan tekanan darah baik tekanan darah sistol maupun diastol. Hasil penelitian ini selaras dengan penelitan yang dilakukan oleh Amanda dan Martini ${ }^{4}$ yang melaporkan terdapatnya hubungan erat antara status gizi (dalam hal ini obesitas sentral yang diukur dengan parameter antropometri) dengan kejadian hipertensi. Dari total sampel yang diambil, sebanyak $76,7 \%$ sampel hipertensi dengan status obesitas sentral atau lingkar pinggang di atas rerata. ${ }^{4}$ Lingkar pinggang dikatakan mempunyai nilai korelasi yang tinggi dengan jumlah lemak intra-abdominal. Jaringan lemak intrabdominal terdiri dari lemak viseral (atau lemak intraperitoneal yang terdiri dari lemak omental dan mesenterial) serta masa lemak retro-peritoneal. Lingkar pinggang berkorelasi baik dengan indeks massa tubuh. ${ }^{6}$

Tekanan darah yang meningkat dapat disebabkan oleh kondisi tubuh karena pada orang dengan lingkar pinggang yang tinggi dapat terjadi peningkatan volume plasma yang menyebabkan kerja jantung menjadi 
bertambah dalam memompakan darah. Hal ini dapat menyebabkan naiknya tekanan darah, Selain itu, obesitas juga dapat meningkatkan risiko penyakit jantung. ${ }^{12,14}$

Lingkar pinggang menunjukkan hubungan erat dengan IMT dan kedua parameter tersebut secara tidak langsung memiliki karakteristik seperti komposisi tubuh yang lebih menggambarkan massa total tubuh. Lingkar perut memiliki sensitivitas dan spesifisitas yang lebih baik daripada ultrasonografi dalam mengukur lemak viseral perut sebagai salah satu faktor risiko penyakit kardiovaskular. ${ }^{15-17}$

\section{SIMPULAN}

Terdapat hubungan antara indeks massa tubuh dan lingkar pinggang dengan tekanan darah pada siswa SMA Kristen 2 Binsus Tomohon.

Pada penelitian lanjut disarankan untuk menggunakan kuesioner dan biodata yang lebih lengkap agar dapat menyingkirkan faktor-faktor risiko yang lain seperti, kualitas tidur dan keturunan hipertensi.

\section{DAFTAR PUSTAKA}

1. Sherwood L. Pembuluh darah dan tekanan darah. In: Ong HO, Mahode AA, Ramadhani D, editors. Fisiologi Manusia: dari Sel ke Sistem (8th ed). Jakarta: EGC, 2014; p. 373-4.

2. Purnayoga B. Hubungan antara indek massa tubuh dengan penyakit arteri perifer di Posyandu Lansia Nusa Indah Desa Pabelan.[Skripsi] Surakarta: Universitas Muhammadiyah Surakarta; 2018.

3. Fauzan E. Hubungan Status Gizi dengan Tingkat Prestasi Belajar pada Siswa Kelas X SMK Negeri 2 Indramayu. Indramayu: ePrints@UNY, 2012.

4. Amanda D, Martini S. The Relationship between demographical characteristic and central obesity with hypertension. Jurnal Berkala Epidemiologi. 2018; 6(1):43-50.

5. Dien NG, Mulyadi N, Kundre R. Hubungan indeks massa tubuh (IMT) dengan tekanan darah pada penderita hipertensi di Poliklinik Hipertensi dan Nefrologi BLU RSUP Prof. Dr. R. D. Kandou Manado. Jurnal Keperawatan. 2014; 2(2).
6. Sumayku IM, Pandelaki K, Wongkar MC. Hubungan indeks massa tubuh dan lingkar pinggang dengan tekanan darah pada mahasiswa Fakultas Kedokteran Universitas Sam Ratulangi. e-CliniC. 2014;2(2).

7. Lumoindong A, Umboh A, Masloman N, Hubungan obesitas dengan profil tekanan darah pada anak usia 10-12 tahun di Kota Manado. eBiomedik. 2013;1:147-53.

8. Balitbang Kemenkes RI. Riset Kesehatan Dasar (RISKESDAS) 2013. Jakarta: Balitbang Kemenkes RI, 2013.

9. Kurdanti W, Suryani I, Syamsiatun NH, Siwi LP, Adityanti MM, Mustikaningsih D, Sholihah KI. Faktor-faktor yang mempengaruhi kejadian obesitas pada remaja. Jurnal Gizi Klinik Indonesia. 2015;11(4):179-90.

10. Amasyitha DF. Hubungan status gizi dengan tekanan darah pada pelajar SMPN 40 Bandung [Skripsi]. Bandung: Universitas Islam Bandung; 2015.

11. Sarah A. Hubungan indeks massa tubuh dengan tekanan darah anak di Sekolah Dasar Negeri 064979 Medan. e-jurnal Fakultas Kedokteran USU. 2013;1(1).

12. Faisal DR, Syarif S. Comparative analysis of anthropometric index to predict hypertension risk in employes Cimahi city 2018. Jurnal Ilmu Kesehatan Masyarakat. 2019;10(1):41-9.

13. Oktaviani WD. Hubungan kebiasaan konsumsi fast food, aktivitas fisik, pola konsumsi, karakteristik remaja dan orang tua dengan indeks massa tubuh (IMT) (studi kasus pada siswa SMA Negeri 9 Semarang tahun 2012). Jurnal Kesehatan Masyarakat Universitas Diponegoro. 2012;1(2).

14. Guyton AC, Hall JE. Textbook of Medical Physiology. Philadelphia: Saunders Elsevier; 2011; p. 162, 198-9.

15. Richard SD, Bungawati D, Pratama KA. Kajian indeks massa tubuh (IMT) terhadap tekanan darah pada perawat di Rumah Sakit Baptis Kediri. Jurnal Penelitian STIKES Kediri. 2011;4(2): 94-103.

16. Seibert FS, Pagonas N, Arndt R, Heller F, Dragun D, Persson P, Schmidt-Ott K, Zidek W, Westhoff TH. Calprotectin and neutrophil gelatinase-associated lipocalin in the differentiation of 
pre-renal and intrinsic acute kidney injury. Acta Physiologica. 2013;207(4): 700-8.

17. Sulastri D, Elmatris E, Ramadhani R. Hubungan obesitas dengan kejadian hipertensi pada masyarakat etnik Minangkabau di Kota Padang. Majalah Kedokteran Andalas. 2012; 36(2):188-201. 